\title{
The warming trend at Helgoland Roads, North Sea: phytoplankton response
}

Received: 17 May 2004 / Accepted: 27 October 2004 / Published online: 27 November 2004

(C) Springer-Verlag and AWI 2004

\begin{abstract}
We combine the temperature and phytoplankton data from one of the longest aquatic data sets in history,

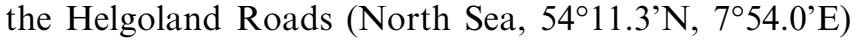
timeseries to evaluate the effects of climate change on the base of marine food webs. The data shows that, despite an obvious warming of $1.1^{\circ} \mathrm{C}$ since 1962 , the mean diatom day of the algal spring bloom is delayed and shifted to the end of the first quarter of the year. This is apparently related to a warming of the autumn (October-December) temperatures. It is the first indication of a warming related shift in phytoplankton succession, the consequences of which would range from lifecycle/food resource mismatches to regime shifts in the North Sea system.
\end{abstract}

Keywords Diatoms - Spring bloom - German Bight · Global warming

\section{Introduction}

We have little information on how the warming trends of the last 10-20 years have affected the food webs of aquatic systems (Cushing 1995; Walther et al. 2002). However, knowledge of how climate warming affects phytoplankton, in its important position at the base of the aquatic food chain, is vital. In contrast, the fingerprints of global warming on terrestrial animals and plants have been well documented (Walther et al. 2002; Parmesan and Yohe 2003; Root et al. 2003).

A pole-ward extension of species ranges and earlier and later onset of spring and autumn events, respectively, have been shown for terrestrial systems. Examples include the flowering of trees, leaf-loss, and bird migration and

K. H. Wiltshire $(\bowtie)$

Biologische Anstalt Helgoland, Alfred Wegener Institute for Polar and Marine Research, P.O. Box 180, 27483 Helgoland, Germany E-mail: kwiltshire@awi-bremerhaven.de

B. F. J. Manly

Western Ecosystems Technology, 217 South First Street, Laramie, WY 82070, USA breeding, (Walther et al. 2002; Hüppop and Hüppop 2003; Parmesan and Yohe 2003; Root et al. 2003). There is some evidence for the persistence of warm-water species and changes in the distribution of zooplankton and phytoplankton in aquatic environments (Straile 2000; Walther et al. 2002). In lakes it has been shown that a warming trend has moved the spring diatom bloom forward by up to 1 month (Weyhenmeyer et al. 1999; Weyhenmeyer 2001). Although fundamental to food web considerations, almost no information exists on the relationship between phytoplankton processes and long-term temperature trends in marine systems, and to date none have been documented for the North Sea. In the past it has been difficult to provide conclusive evidence of a warming trend for the North Sea from real-time measurements (Becker and Pauly 1996; Edwards et al. 2001). This has mainly been because the data series used were relatively short, or because the emphasis was laid on large areas with thermoclines interpolated between the measurement points of sea surface temperature and oceanographic division of water masses. However, since 1873 the surface water temperature of the North Sea at Helgoland $\left(54^{\circ} 11.3^{\prime} \mathrm{N}, 7^{\circ} 54.0^{\prime} \mathrm{E}\right)$ has been recorded on an almost daily basis and provides an excellent basis for the analysis of long-term trends. In addition, in 1962 a long-term pelagic monitoring program, including plankton species composition, was started at the same location by the Biologische Anstalt Helgoland on a work-daily basis (Biologische Anstalt Helgoland 1873-1962; Hickel et al. 1993). Thus, we combined the unique timeseries data for phytoplankton and temperature in the German Bight to assess the effect of a potential warming on the patterns of phytoplankton occurrence.

\section{Methods}

Sampling

Surface water samples were taken (usually before 9 a.m.) on workdays at the Cable buoy site $\left(54^{\circ} 11.3^{\prime} \mathrm{N}\right.$, 
$\left.7^{\circ} 54.0^{\prime} \mathrm{E}\right)$ between the two islands at Helgoland using a bucket. The temperature in the sample was measured immediately. This sample was well-mixed and sub-sampled into a glass bottle for future analyses of nutrients and phytoplankton. The phytoplankton samples taken from this were preserved with Lugols' solution. Using the Utermöhl method and an inverted microscope, $25 \mathrm{ml}$ of samples were counted daily to species level.

\section{Temperature analyses}

Yearly minima, means and maxima $\left({ }^{\circ} \mathrm{C}\right)$ and yearly moving averages were calculated from the data (Fig. 1). The two standard deviation limits around these values indicate the typical variation expected in the absence of any long-term trends, and the moving average indicates short-term changes. Using the temperature data related to phytoplankton data since 1960 , mean monthly temperatures were calculated and subjected to regression analysis to estimate and assess the significance of trends. We fitted models to the data incorporating monthly effects by allowing each month to have a different overall mean value. A time trend was allowed for by fitting linear, quadratic, cubic, quartic and quintic polynomials in terms of the year of observation and autocorrelated regression residuals. We also investigated the applicability of a second-order autoregressive process for errors (Nelder et al. 1996).

Phytoplankton and temperature analyses

Since the timing of the spring bloom is mostly determined using the day of maximum diatom abundance, see e.g. Weyhenmeyer (2001), we first of all evaluated the data to determine a significant maximum. This, however, proved unsupportable as no significant maxima could be calculated. An insignificant positive trend was found. Hence, the maximum diatom day is a poor representation of the actual situation.
Fig. 1 Yearly minimum, mean and maximum temperatures $\left({ }^{\circ} \mathrm{C}\right)$ : filled circles values each year; black lines yearly moving averages; broken line standard deviation limits
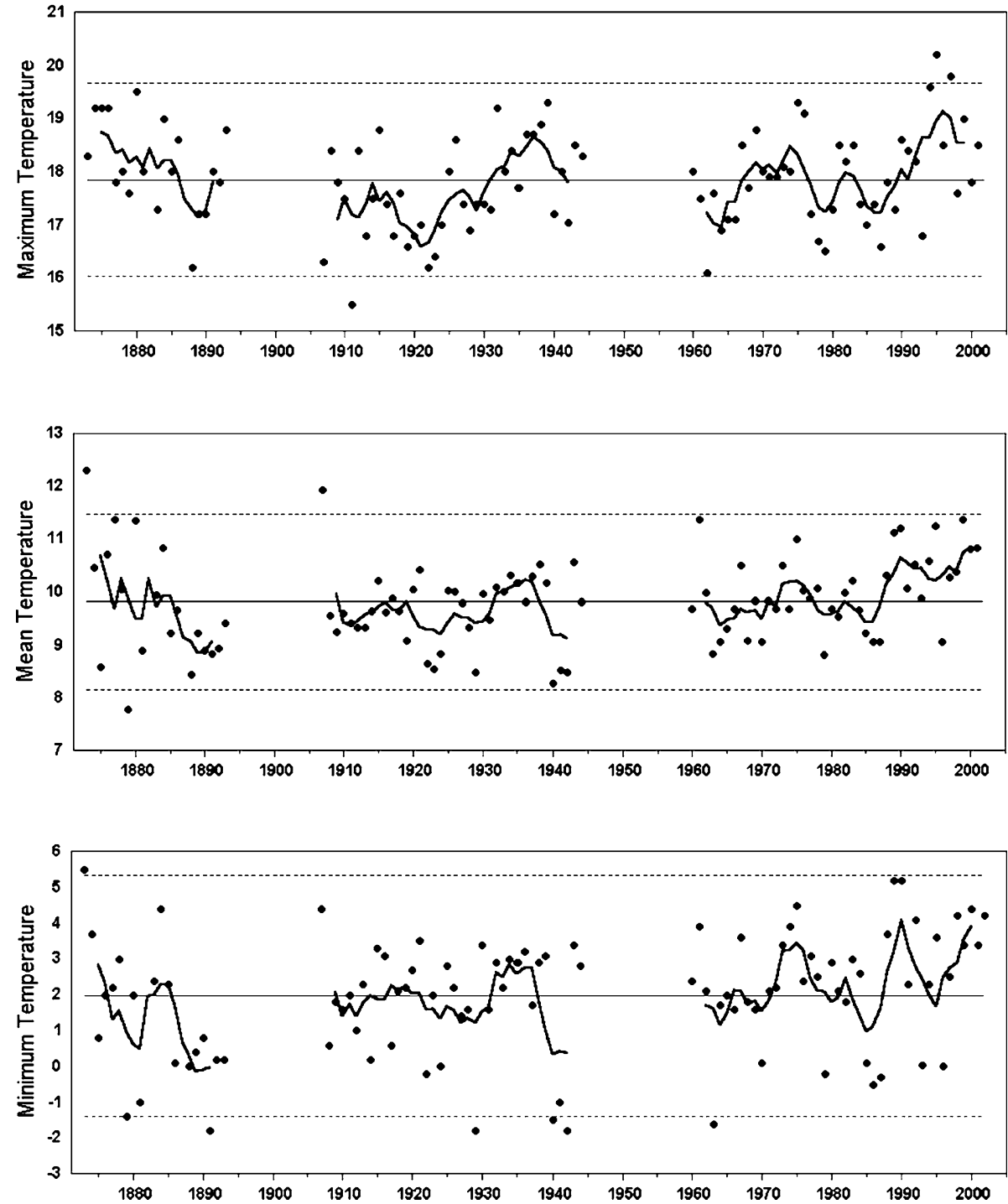
We then computed the mean diatom day (MDD) and the mean diatom count (MDC) in a quarter of each year (January-March, April-June, July-September and October-December). The MDD in a quarter of the year was defined as $\mathrm{MDD}=\Sigma f_{i} d_{i} / \Sigma f_{i}$, where $f_{i}$ is the diatom count on day $d_{i}$ of the quarter, and the sum is over the available samples in the quarter. The second measure, MDC was the mean of the logarithm to base 10 of the count in a quarter of the year. These two measures of the diatom distribution were used to examine how diatom abundance is related to temperature.

The MDD data were related to temperature of that quarter and all previous quarters through a multiple regression. Non-significant effects at the $5 \%$ level were removed from the equation to produce the final fitted model. In most cases, no effects were significant. However, where significant relationships were found then a check was made for autocorrelation in the regression residuals. Where autocorrelation was found, the equation was refitted allowing for this. Similar analyses were carried out with the MDC data. All calculations were carried out in GenStat (Lawes Agricultural Trust 2002).

\section{Results}

The yearly minimum, mean and maximum water temperatures $\left({ }^{\circ} \mathrm{C}\right)$ measured are shown as moving averages with standard deviations in Fig. 1. These show a decline in yearly mean temperatures from 1873 to 1893 , no change between 1907 and 1985, and an increase from 1985 to 2001. The years 1994, 1995 and 1997 had the three highest monthly maximum temperatures. Very cold winters (monthly minimum temperature of $-1^{\circ} \mathrm{C}$ or less) occurred about every 10 years up to 1944 , but only once since 1960.

We concentrate on the temperature readings since 1962 (Fig. 2), and the relationship between this series and the plankton series measured for the same period. A second-order autoregressive process for errors (Nelder et al. 1996) is a good description of the temperature data. The linear trend is highly significant $(P<0.001)$, and the temperature increase is estimated to be $0.0282^{\circ} \mathrm{C}$ per year $(95 \%$ confidence interval $0.0122-0.0422)$, i.e. a

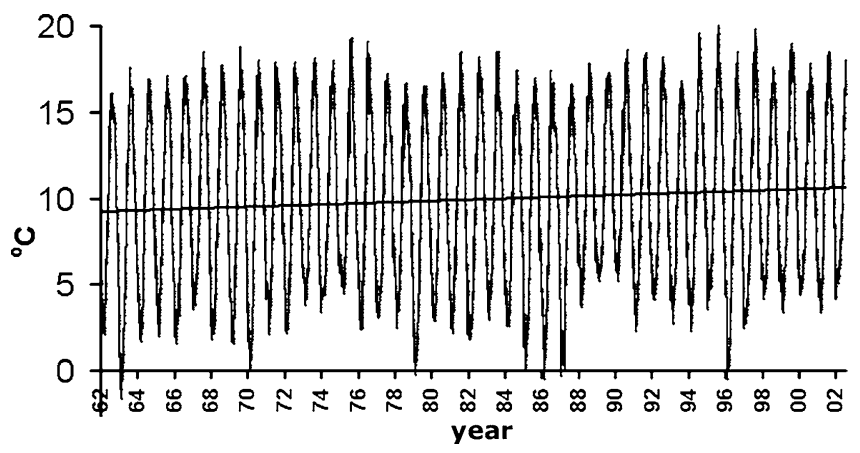

Fig. 2 Water temperature at Helgoland Roads 1962-2002 $1.13^{\circ} \mathrm{C}$ increase for the 40 years since $1962(95 \%$ confidence interval 0.49-1.77).

The motivation for considering two measures of the diatom distribution (MDD and MDC) was the idea, from lakes, that the timing of seasonal diatom blooms will shift with the average temperature, occurring earlier in warm years and later in cold years, resulting in low and high MDD values, respectively. When the quarterly data (January-March, April-June, July-September and October-December) from Helgoland Roads were used to examine the relationship between temperature and the parameters MDD and MDC, we obtained the fitted equations with significant effects as in Table 1. From these equations it is clear that high diatom counts in quarter 1 , and the spring bloom in particular, tend to occur later in cold quarters when the previous quarter was warm. As the estimated effect of the previous quarter temperature (coefficient $=5.06$ ) is larger than the estimated effect of the first quarter temperature (coefficient $=-2.27$ ), this implies that the general warming trend over the past 40 years has caused a shift in the MDD to the end of the first quarter (Fig. 3). The abundance of diatoms also tends to be high in the first quarter of the year when the temperature is cold, but the previous quarter was warm. The fitted equations obtained with significant effects are given in Table 1.

\section{Discussion}

The temperature increase of $1.13^{\circ} \mathrm{C}$ for the 40 years since 1962 in the North Sea at Helgoland is substantial. This concrete increase is new information for the North Sea and conclusively demonstrates the warming trend using data from in situ measurements. It updates the first evaluations made on the warming trend in the North Sea by Becker and Pauly (1996). It compares with a rise in average global temperatures of about $0.6^{\circ} \mathrm{C}$ in the past 100 years (Houghton 2001) and is in line with the warming trends evinced for the measurements in the English Channel (Hawkins et al. 2003), North Sea (Edwards et al. 2002) and North Atlantic (Edwards et al. 2001). The climate anomalies (cold periods) described in the literature for the late 1970s and 1980s are clearly to be seen from the data, although it is also clear that the really cold period was in the early 1960s.

There is a large body of literature relating zooplankton abundances to fish recruitment and how this is affected by climate change in marine systems (Southwood et al. 1988;

Table 1 Relationship between temperature and the parameters MDD and MDC - fitted equations with significant effects. Temp mean temperature in the MDD/MDC quarter; TempB1 value in the previous quarter; TempB2 value in the quarter before that; TempB4 value two quarters before that

Quarter 1 MDD $=17.3-2.27(\mathrm{Temp})+5.06(\mathrm{TempB} 1)$

Quarter 1 MDC $=1.67-0.098($ Temp $)+0.242($ TempB1 $)$

Quarter 2 MDC $=3.85+0.149$ (TempB4)

Quarter $3 \mathrm{MDC}=1.21+0.251(\mathrm{Temp})$ 
Fig. 3 Mean diatom day $(\mathrm{MDD})=\Sigma f_{i} d_{i} / \Sigma f_{i}$, where $f_{i}$ is the diatom count on day $d_{i}$ of the quarter, and the sum is over the available samples in the quarter; Helgoland Roads $1962-2002$

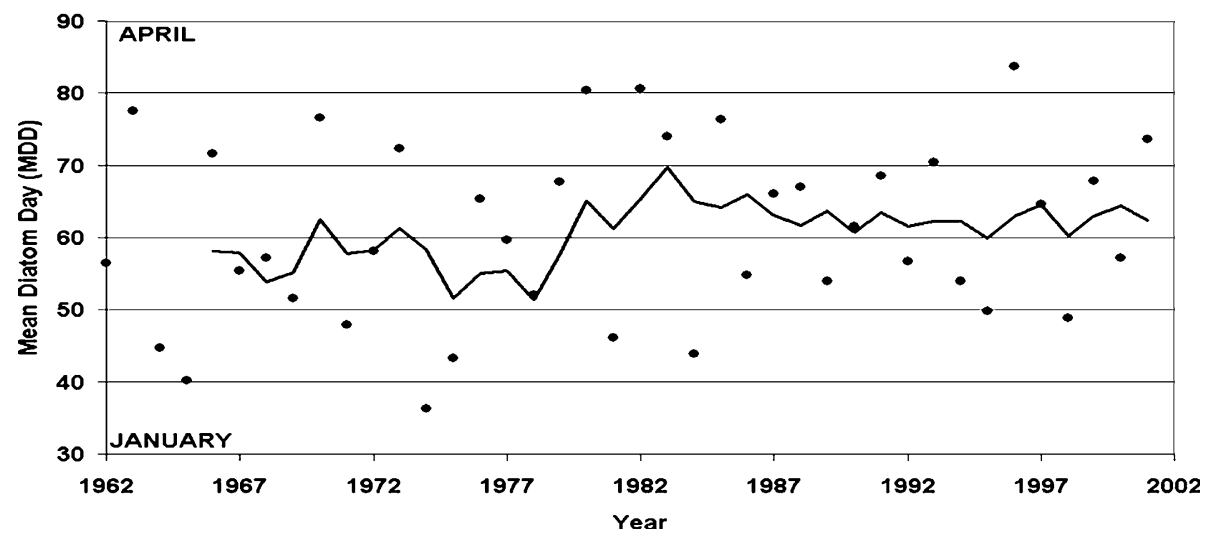

Conover et al. 1995; Beaugrand et al. 2003; Hawkins et al. 2003; Reid et al. 2003). However, there has been no link between the primary producers and temperature, which, because of their pivotal position at the bottom of the food chain function, is crucial. Although there has been some work on phytoplankton abundances in the North Sea inferred from the secondary data related to colour of samples in the continuous Plankton Recorder Surveys (Edwards et al. 2002), our work for the first time combines algal counts from a marine system with the concurrent temperature measurements.

Our work relates the timing and abundance of the spring bloom of diatoms to temperature. We found that, in the German Bight, the MDD of the spring bloom was shifted backwards in cold quarters when the previous quarter was warm, which in terms of biomass emphasis is a shift towards the end of the first quarter. The diatom abundance was high at the beginning of the year, when temperatures are cold, but the previous quarter was warmer. This may be related to the winter trigger mechanisms, such as mixing/stability, which are required for ending dormancy (Itakura et al. 1997; Lewis et al. 1999). It also may be related to the qualitative information we have for Helgoland and for the North Sea of a longer persistence of zooplankton grazers in autumn and early winter which may depress the crucial biomassbuilding phase leading up to a phytoplankton bloom, thus delaying the bloom. The shape of the diatom abundance curve seems to have changed in the first quarter, with a lower lift-off and a sharper angle of increase shifting all the emphasis of the biomass in the first quarter to the end of the quarter (Wiltshire et al. in preparation).

In lakes, the spring bloom is delayed in a cold winter by the formation of surface-water ice and, thus, the reduction of light and the comparably cold water temperatures. A warm winter will prevent this process and also cause changes in the mixing regime (Weyhenmeyer et al. 1999; Gerten and Adrian 2001; Weyhenmeyer 2001). Since the formation of sea ice is rare at Helgoland, a delay of the spring bloom caused by temperatures in the first quarter will only occur in very cold winters, of which there has only been one since 1962 . The winters of 1985-1987 and 1996 were cold, but not cold enough to cause sea ice or to slow phytoplankton growth or affect the timing of the spring bloom. It is unlikely that this delay could be related to changes in stratification, as has been shown for lakes (Straile 2000; Scheffer et al. 2001), as the North Sea is only about $8 \mathrm{~m}$ deep at Helgoland Roads and is generally well mixed. It has been shown that the hydrography of the North Sea has changed (Beare et al. 2002), potentially due to a climate-related increased inflow of Atlantic water into the northern North Sea (Reid et al. 2003). This will also affect the sea around Helgoland. We know from our salinity data that there has been a significant increase in salinity at Helgoland Roads over the last 40 years ( 0.0077 per year) and that the light penetration has also increased by approximately $1-2 \mathrm{~m}$ over this time period. Corroborating this are the observations of the local people at Helgoland, who maintain that the currents at Helgoland and in the German Bight have changed. We are now dealing with clearer, more marine water and warmer conditions, all potentially related to climate changes and the North Atlantic Oscillation (Beare et al. 2002; Edwards et al. 2002; Reid et al. 2003).

Apart from the spring bloom, the timing of diatom occurrences does not generally appear to be related to the temperature at other times of the year. It is interesting that the abundance in the second quarter is strongly related only to the temperature in the same quarter 1 year before, which is perhaps due to the occurrences of the same species in this quarter in each year. The abundance in the third quarter has a simple relationship with the temperature at the same time suggesting that summer temperatures result in a growth of organisms without lags. The abundance in the fourth quarter appears to be unrelated to temperature and it could be expected that zooplankton grazing, for example, has a greater influence on the system.

Work by Edwards et al. (2002) on North Sea phytoplankton abundances inferred from the sample colour in the continuous Plankton Recorder Surveys suggests that the abundance of microalgae is going up in the North Sea. Our data, based on direct counts at Helgoland, does not confirm this. Unlike terrestrial plants, phytoplankton in temperate regions are perhaps the most adaptable of all organisms with regard to temperature shifts. Most of the 
species found at Helgoland Roads also have a large latitudinal range. It is clear that the temperature increase has not nearly reached the limits of the organisms, but that the trigger mechanisms governing phytoplankton events and seasonality have changed substantially. Studies in the Pacific and Atlantic systems showing climate-induced regime shifts (Lluch-Belda et al. 2001; Ottersen et al. 2001; Chavez et al. 2002; Lavaniegos et al. 2002; Link 2002; Marinovic et al. 2002) and the work by Beaugrand et al. (2003) indicate that we may, with this data, be providing the first evidence for regime shifts in the North Sea at the bottom of the food web.

This demonstration of the link between warming and the shift in MDD of the spring diatom bloom, a process that drives our temperate marine ecosystems, is an invaluable step forward. It starts to close one of the most serious gaps (Walther et al. 2002) in our understanding of climate change impacts at the base of aquatic food webs.

Acknowledgements We gratefully acknowledge all those who measured the temperature and counted phytoplankton at Helgoland Roads and who archived their data for further use. In particular, we thank E. Hagmeier, H. Hickel, P. Mangelsdorf, A. Treutner, H. Spindler, S. Janisch and R. Scharek. We thank the crews of R.V. Aade and R.V. Ellenbogen for their dedication to long-term science.

\section{References}

Beare DJ, Batten S, Edwards M, Reid DG (2002) Prevalence of boreal Atlantic, temperate Atlantic and neritic zooplankton in the North Sea between 1958 and 1998 in relation to temperature, salinity, stratification intensity and Atlantic inflow. J Sea Res 48:29-49

Beaugrand G, Brander KM, Lindley JA, Souissi S, Reid PC (2003) Plankton effect on cod recruitment in the North Sea. Nature 426:661-664

Becker GA, Pauly M (1996) Sea surface temperature changes in the North Sea and their causes. ICES J Mar Sci 53:887-898

Biologische Anstalt Helgoland (1873-1962) Long term temperature series of the BAH. In: http://www.bsh.de/de/Meeresdaten/Beobachtungen/DOD-Datenzentrum/index.jsp.

Chavez FP, Pennington JT, Castro CG, Ryan JP, Michisaki RP, Schlining B, Walz P, Buck KR, McFadyen A, Collins CA (2002) Biological and chemical consequences of the 1997-1998 El Niño in central California waters. Prog Oceanogr 54:205-232

Conover RJ, Wilson S, Harding CGH, Vass WP (1995) Climate, copepods and cod: some thoughts on the long-range prospects for a sustainable northern cod fishery. Clim Res 5:69-82

Cushing DH (1995) The long-term relationship between zooplankton and fish. ICES J Mar Sci 52:611-626

Edwards M, Reid P, Plankque B (2001) Long-term and regional variability of phytoplankton biomass in the northeast Atlantic (1960-1995). ICES J Mar Sci 58:39-49

Edwards M, Beaugrand G, Reid PC, Rowden A, Jones MB (2002) Ocean climate anomalies and the ecology of the North Sea. Mar Ecol Prog Ser 239:1-10

Gerten D, Adrian R (2001) Differences in the persistency of the North Atlantic Oscillation signal among lakes. Limnol Oceanogr 46:448-455
Hawkins SJ, Southward AJ, Genner MJ (2003) Detection of environmental change in a marine ecosystem: evidence from the western English Channel. Sci Tot Environ 310:245-256

Hickel W, Mangelsdorf P, Berg J (1993) The human impact on the German Bight: Eutrophication during three decades (19621991). Helgoländer Meeresunters 47:243-263

Houghton JT (2001) Climate change 2001: contribution of working group I to the third assessment report of the intergovernmental panel on climate change. Cambridge University Press, New York

Hüppop O, Hüppop K (2003) North Atlantic Oscillation and timing of spring migration in birds. Proc R Soc Lond Ser B 270:233-240

Itakura S, Imai I, Itoh K (1997) “Seed Bank” of coastal planktonic diatoms in bottom sediments of Hiroshima Bay, Seto Inland Sea, Japan. Mar Biol 128:497-508

Lavaniegos BE, Jimenez-Perez LC, Gaxiola-Castro G (2002) Plankton response to El Niño 1997-1998 and La Niña 1999 in the southern region of the California current. Prog Oceanogr $54: 33-58$

Lawes Agricultural Trust (2002) GenStat Release 6.1. Rothamsted Agricultural Station, Harpenden, UK

Lewis J, Harris ASD, Jones KJ, Edmonds RL (1999) Long-term survival of marine planktonic diatoms and dinoflagellates in stored sediment samples. J Plankton Res 21:343-354

Link JS (2002) Ecological considerations in fisheries management: when does it matter. Fisheries 27:10-17

Lluch-Belda D, Laurs RM, Lluch-Cota DB, Lluch-Cota SE (2001) Long-term trends of interannual variability in the California current system. California Cooperative Oceanic Fisheries Investigations Reports 42:129-144

Marinovic BB, Croll DA, Gong N, Benson SR, Chavez FP (2002) Effects of the 1997-1999 El Niño and La Niña events on zooplankton abundance and euphausiid community composition within the Monterey Bay coastal upwelling system. Prog Oceanogr 54:265-277

Nelder J, Kutner MH, Wasserman W (1996) Chapter 12. In: Applied linear regression models, 3rd edn. Irwin, Chicago

Ottersen G, Planque B, Belgrano A, Post E, Reid PC, Stenseth NC (2001) Ecological effects of the North Atlantic Oscillation. Oecologia 128:1-14

Parmesan C, Yohe G (2003) A globally coherent fingerprint of climate change impacts across natural systems. Nature 421:37-42

Reid PC, Edwards M, Beaugrand G, Skogen M, Stevens D (2003) Periodic changes in zooplankton of the North Sea during the twentieth century linked to oceanic inflow. Fish Oceanogr 12:260-269

Root TL, Price JT, Hall KR, Schneider SH, Rosenzweig C, Pounds JA (2003) Fingerprints of global warming on wild animals and plants. Nature 421:57-60

Scheffer M, Straile D, van Nes EH, Hosper H (2001) Climatic warming causes regime shifts in lake food webs. Limnol Oceanogr 46:1780-1783

Southwood AJ, Boalch GT, Maddock L (1988) Fluctuations in the herring and pilchard fisheries of Devon and Cornwall linked to change in climate since the 16th century. J Mar Biol Assoc UK 68:423-445

Straile D (2000) Meteorological forcing of plankton dynamics in a large and deep continental European lake. Oecologia 122:44-50

Walther G-R, Post E, Convey P, Menzel A, Parmesan C, Beebee TJC, Fromentin J-M, Hoegh-Guldberg O, Bairlein F (2002) Ecological responses to recent climate change. Nature 416:389395

Weyhenmeyer GA (2001) Warmer winters: are planktonic algal populations in Sweden's largest lakes affected? Ambio 30:565571

Weyhenmeyer GA, Bleckner T, Pettersson K (1999) Changes of the plankton spring outburst related to the North Atlantic Oscillation. Limnol Oceanogr 44:1788-1792 